\title{
Expert Advice on Dating and Mating
}

\author{
Paul Hollander
}

Published online: 25 March 2011

(C) Springer Science+Business Media, LLC 2011

While it is axiomatic that none of us are completely autonomous it is not easy to establish precisely how social and cultural forces operate shaping our attitudes and behavior. This is especially the case in the more intimate, personal realms of life, such as the choice of romantic partners. Individual beliefs and attitudes are rarely unique, or totally self-generated - important beliefs and preferences are widely shared in every society and if so, they have common, identifiable origins. In traditional societies it was relatively easy to locate the sources of widely held beliefs and values: it was the family, the community and religion which inculcated and transmitted them. In contemporary, modern societies, and especially the American, the influence of the family, community and church has greatly diminished and it must compete with others more difficult to identify.

\section{Mass Culture and Dating Manuals}

Popular or mass culture (including advertising and self-help books) is the most obvious and direct influence on the attitudes associated with the pursuit of romantic relationships. Although the purveyors of mass culture did not invent, for the most part, the values and attitudes they propagate, mass culture reflects, strengthens, and legitimates prevalent aspirations and beliefs already held whatever their source. Most of the books discussed below are imbued with the spirit and terminology of the market place as they instruct the reader how to sell herself or himself.

P. Hollander $(\bowtie)$

35 Vernon St.,

Northampton, MA 01060, USA

e-mail: hollanderaz@yahoo.com
Widely available books offering advice about dating and the establishment and maintenance of intimate personal relationships are the most tangible expression of present day cultural influences, and especially those among them which are popular. While it would require another study to establish their precise number and circulation, it is safe to say that there are many hundreds, if not thousands of such publications and millions of copies of them are sold every year. The more popular among their authors also disseminate their message on television for even larger audiences.

It is not difficult to place this literature in the broader cultural currents of American social history in which egalitarianism combines with individualism and everybody is believed to have limitless potentials not only for amassing great fortunes but also for establishing long lasting, loving relationships. These books serve up a reincarnated myth of the self-made man, (and woman) but the self-improvement they champion is not aimed at getting rich but getting the love we supposedly all deserve.

It is the widely recognized and much lamented confusion and uncertainty regarding the best ways to establish and maintain close personal relationships that creates the huge demand for advice and instruction. When traditional sources of guidance are weakened and discredited - as they have been for some time - the wisdom of "experts"credentialed or self-styled - is sought. As Barbara Whitehead points out, at the present time "there are no models to follow... The process of finding a life partner is often chaotic, unintelligible... There are no common standards or codes of behavior..." In turn Laura Kipnis writes:

relationship advice is a booming business these days: between print, airwaves and the theraphy industry, if there were any way to quantify the GNP in romantic counsel...it would certainly amount to a staggering 
number... Eager to be cured of love's temporality, a desperate population has molded itself into... advice receptacles ... Check out the relationship self-help aisle in your local bookstore chain.

Kipnis believes that present day American society seeks to indoctrinate its members with the importance of love, conventionally defined: "Consider the blaringly omnipresent propaganda beaming into our psyches on an hourly basis; the millions of lovestruck couples looming over us from movie screens, televisions, billboard, magazines, incessantly strongarming us onboard the love train. Every available twodimensional surface touts love."

Several of the books discussed below (selected from a much large number of such publications) combine discussion of finding partners with improving existing marital relations. These books have been written by both men and women, probably more by women and most of them for women. The authors are therapists, psychologists, and psychiatrists with or without Ph.D.-s, occasionally MD-s, as well as freelance writers and journalists without proper credentials who believe themselves to be qualified to dispense such advice. We do not know how many of these authors personify the advice they give.

It is noteworthy that even in our times marked by the success of feminist movements and beliefs it remains a prevailing assumption in much of this literature that women are more interested in creating and maintaining romantic relationships than men and more eager recipients of advice that is supposed to help them to attain this goal.

The influence of these authors is enhanced by their lecture tours, seminars and frequent appearance on television. While we can never determine with any precision how much influence ideas exert on belief and behavior it is plausible that widely read and widely watched authors wield some influence. People vote with their money expressing hope or trust in their message when they buy their books, enlist in their seminars and watch them on television.

There is one preeminent feature these books share: it is the focus on methodology, on techniques and carefully specified steps or stages in the process of finding a partner and developing a good relationship.

\section{Closer Look at Expert Advice}

Dr Phil McGraw (also known as "Dr Phil") is a preeminent authority on matters of the heart. Author of twelve self-help books (including three on diet and weight loss) he has been on the New York Times best seller list and is "host of the nationally syndicated, daily one-hour series, $\mathrm{Dr}$ Phil" the jacket of one of his books here discussed (Love Smart) informs the reader. He obtained a Ph.D. in clinical psychology from the University of North Texas but stopped practicing in 1990 after he set up a trial consulting business. His claim to fame is closely associated with his friendship with Oprah Winfrey and his frequent appearances on her show before he had his own. He profusely thanks her in the Acknowledgments for her "friendship and endless belief and support of my work. You make this world a better place....You have made a difference not only in this country, but also in the cradle of humanity by leading by example and living with completeness and honesty."

Dr Phil's credentials include a marriage of 30 years he extols in the Acknowledgments: "Robin, [wife] you are the culmination of what anyone reading this book would pray for. Our relationship has been the crowning achievement in my life..." He makes no reference to an earlier failed marriage that lasted for 3 years.

This book, as several others of the same genre, is written for women. Its surprising premise-in 21 st century America - that, unlike men, women long for getting married and badly need instruction about the methods which will accomplish this goal.

Dr Phil does not shy away from making bold claims and promises delivered in a folksy style that brings to mind the proverbial used car salesman all the more since he favors the metaphors of salesmanship. To wit:

If you cant find the guy you want, or dont know how to fix the guy you got, you and I are about to change that in a major way...

...I am about to let you in on some secrets and strategies...

You are about to master the art of relating. You are about to get your relationship 'black belt.'...the problem is not you...

I believe, to the absolute core of my soul that you are about discover a huge secret...: YOU.

To get you where you want to go, we're going to absolutely rewrite the script of your life, and you're going to be the star...

In a section entitled "Your Defined Product" Dr Phil advises to master "the first rule of the game, which also happens to be the first rule of sales: If you're not sold on your product, you won't be able to sell anyone else on it either." The same message is repeated later in different words: "Thinking like a winner, feeling like a winner and behaving like a winner are essential to victory."At the end of the book he writes: "here is the chapter where you cash in your chips. The one you have been waiting for on how to reel him in.... Now it seems time to...close the deal..." 
The bulk of these exhortations are remarkably unoriginal and reduce to repeated, self-confidence building mantras:

You will not succeed in the highly competitive dating game unless you are convinced that you are absolutely fabulous....I'm going to show you how to discover the fabulous parts of you...

If you will embrace the concepts that I'm about to lay out, adopt the behaviors that I'm going to prescribe and employ the strategies that we're going to create together: problem solved! ... and what's more, we are going to have an absolute ball doing it. It's time to get what you want!... you have to decide that you are fabulous...If you truly want to get the fish into the boat you're going to have to fall in love with yourself...

More specifically he advises:

You think you're fat and ugly-Baloney!... To the right guy, those extra pounds look like feminine curves. And while that face you see day in and day out may have worn out its welcome with you, in the eyes of the right man, it's unique, character-filled, quirky or wise...

A great self-image will beat out collagen injections and silicone implants... If you want to show the world that you have everything to give and nothing to lose, follow the example of powerful people.

Donald Trump is one exemplar mentioned.

The abundance of practical advice includes making lists of all sorts of things to ponder and most of all, specifics of self-presentation, for example: "Eye contact is an especially powerful presentation tool... ... you choose what type of presence you want to radiate in a room... Don't just show up at a social situation... Create your sound bite. Explain who you are in twenty words or less. Make yourself sound as exciting as possible... Define four or five things you can talk about at any time to anyone ... There are positions that are likely to get you in someone's crosshairs in no time: sitting at the center of interaction in a heavily trafficked area; Sitting at the bar..."

Dr Phil's confident exhortations are firmly rooted in the boundless American belief in the capacity of the individual to remake or reinvent herself: the past is irrelevant, as are our genes, upbringing and environment; the power of our fee will is all that matters, and it is unlimited. All of us have something wonderful about us. It is not easy to imagine and impossible to know how a book of this kind helps the readers to establish rewarding and durable relationships.

Mars and Venus on a Date by John Gray is subtitled $A$ Guide for Navigating the 5 Stages of Dating to Create a Loving and Lasting Relationship. This manual instructs the reader in great detail what she or he should, or should not do in the process of finding a "loving and lasting relationship." The book is relentlessly focused on techniques, communication, the sober calculation of ends and means and the profound differences between men and women. Men are coached about the kind of compliments they should offer to women and vice versa. There are several pages listing specific places, occasions or activities recommended for meeting "your soul mate." They include "hanging out on an airplane near the rest rooms and strik[ing] up conversation while waiting in line... In a restaurant a woman should get up several times and walk to the restroom so that a man has a chance to see her and be interested."

Romantic notions of love are prominent and there is much talk about "chemistry" and "soul mates." Gray writes: "When soul mates fall in love there is simply a recognition. It is as clear and simple as recognizing that the sun is shining today..." He proposes that "we cannot create emotional, mental, or spiritual chemistry. It just is." This author is among those who believe in the romantic marriage with "a partner with whom our love and passion can grow." More conventionally he also believes that women should "play hard to get," - or as he puts it "when a woman is too eager to please, a man doesnt experience the distance he needs to pursue her."

Dr Joyce Brothers, author of several bestselling "relationship books," is described on the jacket of one of them (What Every Woman Ought to Know...) as a "celebrity and a unique authority figure in the lives of countless people." As most of advice manuals it begins and ends on an upbeat note: "The good news is that...there are hundreds and thousands of $\mathrm{Mr}$ Rights for each and every woman." Dr Brothers is convinced that "the early ecstasy" and "rapture" of sex can be recaptured with some prudent initiatives such as weekends away from home or a "second honeymoon...recharging sexual batteries... is easier than you think."

Her approach combines hard-nosed practicality with somewhat old fashioned notions of the man-hunt: "The office is not the only place where eligible men abound. Hospitals are full of male doctors and medical students, male patients and visitors. You might think of volunteering... at your local hospital a few hours a week." Readers are not only instructed in the techniques of the man-hunt, they are told what to look for: "The qualities to look for in a man are sincerity, warmth, integrity, courage, gentleness, perseverance, sympathy, intelligence." Written in the early $80 \mathrm{~s}$ this book shows few signs of radical feminism as it repeatedly advises women to cater to male egos, take the extra steps to make their spouses happy (e.g. have sex even if they don't feel like it) and treat their marriage as more important than their career (if they have one). 
The optimistic approach also finds expression in emphasizing the redeeming value of communication that leads to problem-solving: "Sex is not that complicated a deal. If you tell each other in a loving way what is good and what leaves you cold, you will be surprised how fast things will improve." This is one of many books which both reflect and reenforce American cultural values and attitudes: individualism, egalitarianism, optimism, practicality, belief in being methodical, high expectations tempered by sober calculation.

A more recent popular book entitled He's just not that into you: the no-excuses truth to understanding guys ("No.1 New York Times Bestseller" also made into a movie) is dedicated to the proposition that women make poor judgments about men and deserve better treatment than they get from them; they need the advice and help the authors offer. According to the cover information, the book is "based on a popular episode of "Sex and the City" the television program. The authors also appeared on the Oprah Winfrey Show-we do not know if that was a reflection of the success of the book, or the decisive event that established its popularity. While much of the book abounds in humorously presented common sense advice, more unusually the authors insist that "if a man is not trying to undress you, he is not into you" and "if a man likes you, he's going to want to have sex with you." They assure the readers that they have a "right to have a fantastic sex life."

The question raised by the popularity of this book, why is there a large demand for advice predicated on the poor judgment of women about men? The apparent existence of a large pool of such women is counter-intuitive in our era of liberated women.

The authors of The Rules - another highly popular and controversial bestseller-aver that "When you do The Rules, you don't have to worry about being abandoned, neglected or ignored!" They promise that "abuse doesnt happen in a Rules relationship because when you play hard to get and he works like hell to get you, he thinks you're the most beautiful, wonderful woman in the world, even if you are not. He treats you like a precious jewel." Adopting The Rules will result in "living painfree. No more lonely Saturday nights, no more waiting for the phone to ring... To be adored and secure at last! That's the incredible payoff you get when you do The Rules..."

This book has in common with most others a didactic and repetitive style but is more unabashedly manipulative than most: "The Rule is that as long as you don't outright lie, you neednt be honest to a fault either." It also has in common with similar books the emphasis on techniques, self-esteem building and the purported belief in the limitless possibilities available for all those willing to abide by the advice proffered. Its main distinction lies in the unembarrassed advocacy of the "playing hard to get" strategy and a largely conventional view of sex roles: “...the premise of The Rules is that we... trust in the natural order of thingsnamely, that man pursues woman..." Women "should be a mystery" not an open book, seemingly unattainable, somewhat distant, emotionally reserved in their self presentation. These manipulative and hardnosed admonitions make The Rules an exceptionally unromantic text that endlessly warns against the dire results of spontaneity, openness and sincerity ("letting it all hang out... is counterproductive to your goals." It advocates relentless calculation, pretense and "go[ing] against your feelings," at any rate in the early stages of the dating campaign. Sex should be withheld or carefully rationed, women should not "give it away" prematurely but use it as part of the grand strategy of getting married to the most suitable partner. The authors "believe in treating dating like a job, with rules and regulations. Just like you have to work from nine to five, no matter how you feel, we believe you have to silently train men to make plans with you (elusive, busy, happy you!)..." They warn against discussing their book with a therapist who is likely to consider it "dishonest and manipulative." A good guess.

The endless confidence building exhortations merge into unabashed manipulativeness and the conflation of "is" and "ought:"

Act confident even if you don't feel it...

Being a creature unlike any other is....an attitude, a sense of confidence and radiance that permeates your being...It doesnt matter if you are not a beauty queen, that you never finished college, or that you don't keep up with current events... Of course that is not how you really feel. This is how you pretend you feel until it feels real. You act as if!... You act as if everything is great, even if you are on the verge of flunking college or getting fired... You tell yourself 'Any man would be lucky to have me' until it sinks in and you start to believe it.

What the authors do not to tell the hapless reader is what will enable her to conjure up these flattering and unrealistic self conceptions. They are reduced to advising the reader to repeat to herself how terrific she is and urge her to "read this book over and over until you have practically memorized it, then practice the principles as much as possible."

The huge commercial success of The Rules inspired The Rules: More Rules to Live and Love By published 2 years later in 1997. Interestingly the authors inserted a disclaimer in the beginning: "We are not licensed to practice psychology, psychiatry, or social work, and The Rules is not intended to replace psychological counseling, but is simply a dating philosophy based on our own experiences and those of thousands of women who have contacted us." 
The authors also published a follow-up volume on internet dating that largely duplicates the advice offered earlier in the books discussed above.

The Five Love Languages is one of eight books by Gary Chapman which achieved best seller status and has been on the paperback bestseller list of the New York Times for 118 weeks. It is not addressed to those seeking a partner but to those who are interested in improving an existing marital relationship. The author is director of Marriage and Family Life Consultants Inc., travels around the world presenting seminars and his radio program airs over 100 stations - the cover informs the reader. He takes a critical view of romantic love ("it tends to disengage our reasoning abilities") and cites studies which show that it rarely endures for more than 2 years. The goal of the book is to keep love alive in marriage after the romantic fog dissipates.

The Complete Idiot's Guide to Dating is an ambitious undertaking despite its title, "...intended for everyone looking for love-whatever your age, background, dating history, or sexual preferences or intentions." Even seniors are advised how to make "the most of the golden years." There are chapters on "Unraveling the Mystery of Attraction,"“Diversity Dating," "Where to Meet People," "Putting the Best You Forward," "From Shy to Social Butterfly," "The Art of Flirting," "Handling Rejection" and many others.

In the preface the author writes: "With every page of this book, feel my pledge to you for the hope, strength, and empowerment to free your spirit, enrich your soul, make your dreams come true, and give and receive the love you want and deserve." From the back cover we learn that " Dr Judy...is a clinical psychologist, sex therapist, dating expert and media personality ... A pioneer of radio advice talk... she answers questions from millions of callers..." She appeared on many popular television talks shows and also leads classes at various seminar centers on "How to Marry a Millionaire." This book also offers advice about accomplishing this goal.

The overarching emphasis on methodology is exemplified by almost an entire chapter devoted to conversation openers subdivided into "charming romantic openers, selfdisclosure openers, conversation openers." There are "Ten commandments" to govern the initiation of sexual relations and "nine phases of dealing with rejection" and "18 tips for letting go." This mania to number of everything is common to self-help books and is likely to be intended to make the instructions and exhortations easier to memorize and to add a semblance of coherence and organization.

It is her essential message "that the key to success is to be happy with yourself." She is among the many writers of self help books who seem to believe that nobody has a good reason for an unfavorable self-conception. She ends with urging the reader to read more of her books.
Once more, it is difficult to put down this book without wondering whether or not, or to what degree the author truly believes that it will make a difference to the lives of people who read it. For better or worse, it is likely that she does.

The Complete Idiot's Guide to Perfect Marriage is of the same series and has the same format as the Guide discussed above. Its authors assure the reader at the very beginning that "...we will teach you everything you need to know to make your marriage strong, stable and more passionate than you ever dreamed possible." The introduction promises "a relationship makeover." Chapter titles are informative of the nature of the volume: Chapter 1: "Profile of the Perfect Marriage;" Chapter 4: "Making the Ordinary Extraordinary;" Chapter 5: "Keeping the Passion Alive;" Chapter 29: "Soul Mates."

The Sistahs' Rules-Secrets for Meeting, Getting and Keeping a Good Black Man is written for black women and warns, as stated on the cover, that it is "Not to be Confused with The Rules." The humorous guidance here offered is not significantly different from what is offered in the other volumes which do not have a racially defined audience. But there is a greater emphasis on finding "a good man," that is to say, an emphasis on what "really matters"-personality, character, trustworthiness-rather than social status and things material. These oft-repeated exhortations suggest, not surprisingly, that many black women harbor mobility aspirations which may exceed those of their white counterparts. Still, lowering expectations is the key to finding the right man: "we're all too often held our potential mates up against the Knight of the Shining Armor standards...a fantasy wish list that's sentencing us...to the singles-only line." The author also warns against the kind of men "who tells you he would have graduated from high school but he left in protest because the teachers were racist" or against the type who "whenever a cop car drives by...slouches in his seat and pulls his hat down over his face."

There are strictures against applying white standards of beauty: readers are assured that kinky hair and large bottoms are nothing to be ashamed of, in fact "black men will do anything... to please a woman with a big butt. And we as black women, need to take advantage of that." No concern here with racial stereotyping. The "potential Brother Mr Right"-a version of the renaissance man - "loves God and recognizes that there is a higher being in control of our destinies" and "he likes oral sex-and loves performing it."

One of the authors (Myreah Moore) of Date Like a Man is credited with helping "thousands of women find the soul mates through her personal training sessions and public seminars" according to the jacket. The other, Jodie Gould "an author and writer specializ[es] in relationships and popular culture." The very first paragraph exudes the upbeat tone as readers are being congratulated for being 
single: "This can be the best time of your life. Being single allows you to discover who you are... and what you truly need from a man." The usual exhortation to avoid negative thoughts follow and the "promise that if you follow my advice and do the exercises in this book, you will feel better about yourself and the men you date. Once you learn to treasure yourself, people will move mountains to be close to you." The author believes "that every woman should date a minimum of one hundred men before she chooses a mate." There are numerous specific instructions about the use of body language to attract men. They include: "stand with one hand on your hip... cross and uncross your legs when you are wearing a dress... wet your lips with your tongue...toss or flip your hair...play with a cylindrical object such as a pencil, pen or stem of a wineglass. This reveals your subconscious desires... dangle one shoe while seated in a relaxed position..."

The best selling The Ten Commandments of Dating: Time Tested Laws for Building Successful Relationships is inspired by Christian beliefs. One of the authors, a minister directs a ministry of 5000 at Second Baptist Church in Houston, TX; the other author is a licensed clinical psychologist in private practice in Austin TX. Another volume inspired by strongly held Christian beliefs is entitled No More Sheets: The Truth About Sex written by Juanita Bynum identified on the jacket as the "dynamic founder and president of the Juanita Bynum Ministries, in Waycross Georgia, Prophetess [sic] Bynum travels the world over delivering an annointed message..." The book "has sold millions of copies! She can be seen on her weekly television program on the Black Entertainment Television network..."

The Thrill of the Chaste: Finding Fulfillment While Keeping Your Clothes On was written by a Jewish born rock journalist who became a born again Christian at age 31. Another book advocating chastity is entitled Been There, Havent Done That: A Virgin's Memoir the author is described on the cover as "a Harvard educated, worldtraveled, attractive young woman of twenty five."

At last it is instructive to examine a book of similar purpose published over half a century ago, The Art of Dating. It was based on its author's effort to respond to the concerns of young people expressed in over 17,000 questions she collected. This book is distinguished by a tone of moral certainty and an apparent conviction that social-cultural norms and standards have a robust and legitimate existence and individuals are rightly expected to conform to them. There are frequent references to what is and is not "socially acceptable" and to the importance of preserving a good reputation, especially for girls. Correspondingly "responsible" and "responsibility" are among the most often used words in this volume-words rarely, if at all, encountered in the contemporary "relationship books." (For example "responsi- ble fellows and girls feel that their homework comes first...") The author strongly supports the idea to confine "one's social life to acceptable circles and one's friendships to those who are vouched for upon introduction."

Young readers are cautioned and instructed about "what is acceptable in this delicate area of a relationship" that is to say, matters sexual. Premarital chastity is highly recommended. Matters taken for granted by the author provide excellent illustration of the social-cultural changes which transpired over the past half century and have made many of the author's ideas and injunctions quaint and obsolete. They include the proposition that "a man and a woman are expected to observe the sexual restraints of their society" and the numerous references to the indispensability of parental approval of whom to date. The book recommends serious preparation for marriage "in much the same way that any other job does."

Unlike the other books here considered this volume is permeated by a deterministic view of the world: people are seen as operating within well defined, taken for granted and benign cultural norms and conventions, rebellious nonconformity is rejected. At the same time this book also suggests (as do the other writings) that virtually everything is up to the individual, to his or her will and persistence to succeed. It is a contradiction that came to be prominent in American culture since the 1960s when preoccupation with the many possibilities of self-realization came to be coupled with a new concern with the ever present threats of a profoundly repressive social order.

\section{Advice and Behavior}

All the books here discussed (as well as others excluded for limitations of space) are upbeat, cheery, and repetitious, they radiate and recycle commonsense propositions and focus on the techniques of finding a romantic partner. Their other striking commonality is the refusal to concede that human attitudes and behavior are to some (much debated) degree socially and cultural determined (the only exception was The Art of Dating published half a century ago). These authors affirm and reaffirm that the individual can accomplish virtually anything she or he wishes to, including the acquisition of a high degree if self-esteem, and finding a compatible, loving partner. These books fit into the long tradition of the American belief in self-help and self reinvention that found expression in 19th century self help books dealing not with emotional fulfilment (by finding a romantic partner) but with ascending the ladder of social hierarchy to wealth and power.

The major explanation of the large volume of these repetitive messages is likely to be found in the perplexities of modernity, and especially the spread of individualism 
and the related therapeutic orientation, the belief that most of our problems and difficulties have psychological origins and psychological remedies. This orientation helps to explain the unrealistic belief that improving self-esteem is the key to success both in regard to socio-economic advancement and emotional gratifications, and that such improvements are within the reach of everyone. This modern therapeutic approach has merged with the selfhelp tradition. The intact preservation of this tradition in these books is all the more remarkable since they were written in the last third of the 20th century and the early 21 st, periods marked by the spread and institutionalization of the belief in the overwhelming social and cultural determination of individual lives and in the powerlessness of the individual confronted by social forces. Affirmative action, identity politics, political correctness and the associated policies have all been based on the premise that individual will and determination count for little in shaping one's life. Evidently the writers of these books have not been influenced by these, by now axiomatic beliefs, or they may believe that they do not apply to intimate personal lives and relationships in which social position and background is negated (or ought to be negated) by individual will and determination and by a properly positive outlook.

One comes away from reading these books with a bemused disbelief wondering if they have a significant impact on their readers, let alone provide effective help to establish durable romantic relationships. Whatever their impact on behavior they reflect with striking uniformity major and longstanding cultural assumptions of American society.

\section{Further Reading}

Brothers, J. 1984. What every woman ought to know about love and marriage. New York.

Chapman, G. 2004. The five love languages: How to express heartfelt committment to your mate. Chicago.

Duvall, E. M. 1958. The art of dating. New York.

Gray, J. 1997. Mars and Venus on a date. New York.

Kurlansky, J. 2003. The complete idiot's guide to dating. New York.

McGraw, P. 2005. Love smart: Find the one you want; fix the one you got. New York.

Fein, E., \& Schneider, S. 1995. The rules: Time-tested secrets for capturing the heart of Mr Right. New York.

Whitehead, B. D. 2002. Why are there no good men left: The romantic plight of the new single woman. New York.

Paul Hollander is the author or editor of 14 books on political and cultural topics including characteristics of contemporary American society and culture. This article is adapted from his forthcoming book, Extravagant Expectations: New Ways to Find Romantic Love in America (Ivan R. Dee). 